NBER WORKING PAPER SERIES

ASSET PRICES IN A LIFECYCLE ECONOMY

\author{
Roger E.A. Farmer \\ Working Paper 19958 \\ http://www.nber.org/papers/w19958 \\ NATIONAL BUREAU OF ECONOMIC RESEARCH \\ 1050 Massachusetts Avenue \\ Cambridge, MA 02138 \\ March 2014
}

I would like to thank C. Roxanne Farmer for her editorial assistance. The views expressed herein are those of the author and do not necessarily reflect the views of the National Bureau of Economic Research.

NBER working papers are circulated for discussion and comment purposes. They have not been peerreviewed or been subject to the review by the NBER Board of Directors that accompanies official NBER publications.

(C) 2014 by Roger E.A. Farmer. All rights reserved. Short sections of text, not to exceed two paragraphs, may be quoted without explicit permission provided that full credit, including $(\subset$ notice, is given to the source. 
Asset Prices in a Lifecycle Economy

Roger E.A. Farmer

NBER Working Paper No. 19958

March 2014, Revised March 2014

JEL No. G0,G12

\begin{abstract}
$\underline{\text { ABSTRACT }}$
The representative agent model (RA) has dominated macroeconomics for the last thirty years. This model does a reasonably good job of explaining the co-movements of consumption, investment, GDP and employment during normal times. But it cannot easily explain movements in asset prices. Two facts are hard to understand 1) The return to equity is highly volatile and 2) The premium for holding equity, over a safe government bond, is large. The equity premium has two parts; a risk premium and a term premium. This paper constructs a lifecycle model in which agents of different generations have different savings rates and I use this model to account for a high term premium and a volatile stochastic discount factor. The fact the term premium is large, accounts for a substantial part of the observed equity premium.
\end{abstract}

\author{
Roger E.A. Farmer \\ UCLA \\ Department of Economics \\ Box 951477 \\ Los Angeles, CA 90095-1477 \\ and NBER \\ rfarmer@econ.ucla.edu
}




\title{
ASSET PRICES IN A LIFECYCLE ECONOMY
}

\author{
ROGER E.A. FARMER
}

\begin{abstract}
The representative agent model (RA) has dominated macroeconomics for the last thirty years. This model does a reasonably good job of explaining the co-movements of consumption, investment, GDP and employment during normal times. But it cannot easily explain movements in asset prices. Two facts are hard to understand 1) The return to equity is highly volatile and 2) The premium for holding equity, over a safe government bond, is large. The equity premium has two parts; a risk premium and a term premium. This paper constructs a lifecycle model in which agents of different generations have different savings rates and I use this model to account for a high term premium and a volatile stochastic discount factor. The fact the term premium is large, accounts for a substantial part of the observed equity premium.
\end{abstract}

\section{INTRODUCTION}

The dominant macroeconomic representative agent, $(R A)$ model of the last thirty years assumes that the co-movements of aggregate consumption, investment, GDP and employment behave as if they were chosen by a representative agent who maximizes the expected discounted sum of a stream of future utilities. Although the RA model can capture the volatilities and co-movements of aggregate quantities during 'normal times', it cannot easily explain movements in asset prices. ${ }^{1}$ Two facts, in particular, are hard to explain.

The first fact is that the stock market is highly volatile and daily movements in the average price of stocks are much too large to be accounted for by movements in future earnings (Leroy and Porter, 1981; Shiller, 1981). To explain this excess volatility puzzle the rate at which agents discount the future must be stochastic and

Date: March 17, 2014.

I would like to thank Markus Brunnermeir, Xavier Gabaix, Valentin Haddad and Pawel Zabczyk for their comments on an earlier draft of this paper. I would also like to thank C. Roxanne Farmer for her editorial assistance.

${ }^{1}$ The Great Depression of the 1930s and the Great Recession of 2008 are clearly not 'normal times' and the fact that the RA model does not explain those episodes suggests that we need to rethink the foundations of macroeconomic theory in a more radical way. That topic, which I have discussed in other work (Farmer, 2012), is beyond the scope of the current paper. 
highly volatile. In a representative agent economy, the stochastic discount factor is a function of aggregate consumption, and when the utility function of the representative agent is calibrated to a reasonable degree of risk aversion, the observed volatility of consumption is not large enough to account for observed price volatility in the data.

The second fact is that the return to holding a risky asset has historically been six hundred basis points higher than the return to holding government bonds (Mehra and Prescott, 1985). To explain the equity premium puzzle, the covariance of the rate of return on a risky asset with the agent's marginal utility of consumption, must be large. It is hard for the RA model to explain a six hundred basis point equity premium because asset prices do not covary enough with marginal utility for any reasonable model of preferences.

Much of the empirical work in the literature on the equity premium does not distinguish between the premium that arises from the fact that a dividend stream is random and the premium that arises from the fact that it is paid at different times. The former is a risk premium; the latter a term premium. Abel (1999) offers a theoretical framework for understanding the difference between these two concepts and he points out, that in U.S. data, the premium for holding long-term government bonds over short-term government bonds has historically been of the order of $1.7 \%$.

In this paper I construct a lifecycle model that successfully explains both volatile asset prices and a substantial term premium as equilibrium responses to purely nonfundamental shocks. ${ }^{2}$ In simulated data, my model can account for a Sharpe ratio of 0.29 which is more than half of the annual value in U.S. data. Further, it can account for an equity premium on leveraged equity of $3.5 \%$, in a model where there is no fundamental uncertainty and where agents are risk neutral. ${ }^{3}$

\footnotetext{
${ }^{2}$ Cass and Shell (1983) use the term intrinsic uncertainty, to refer to anything that affects preferences, endowments or technology, and they use the term extrinsic uncertainty, or sunspots, to refer to anything that doesn't. Azariadis (1981) uses the term self-fulfilling prophecy to refer to sunspots. In this paper I will use the term fundamental shock, to refer to intrinsic uncertainty and non-fundamental shock to refer to extrinsic uncertainty or sunspots. These terms are, I believe, more commonly accepted in the literature.

${ }^{3}$ The Sharpe ratio is the sample average of the difference between the risky rate and safe rate of return divided by the standard deviation of the risky rate. It is a better measure of the return difference between two assets because, unlike the equity premium, the Sharpe ratio cannot be increased by leveraging a risky portfolio through borrowing.
} 
In my model, agents have recursive preferences with an elasticity of substitution of 1 , and a risk aversion coefficient of 0 . This subset of Epstein-Zin preferences is attractive because it admits closed form solutions to individual maximization problems. ${ }^{4}$ In addition to this preference assumption, I set the discount factor to 0.97 , and I choose two parameters to match an average working life of 45 years and an average time spent in retirement of 15 years. These three parameters, plus the standard deviation of non-fundamental shocks, are the only parameters of my model economy.

\section{Relationship to the Literature}

There is a large literature on asset price puzzles summarized by Campbell (2003). The current consensus amongst finance economists, as laid out by John Cochrane (2007) in his Presidential Address to the American Finance Association, is that most of these puzzles occur because of unexplained movements in the stochastic discount factor.

The excess volatility puzzle and the equity premium puzzle are related to each other and both puzzles are connected to our lack of understanding of why the stochastic discount factor moves around so much. A large equity premium implies that the covariance between the marginal utility of consumption and the stochastic discount factor must also be large. Because the covariance of two random variables is bounded by the product of their individual standard deviations, a high equity premium implies that the marginal utility of consumption, or the stochastic discount factor, or both, must have a large standard deviation. The bounds placed on the equity premium by this condition are known in the literature as the Hansen-Jagannathan bounds (Hansen and Jagannathan, 1991).

Constantinides (1990) and Abel (1990) have proposed resolutions of the equity premium puzzle by modifying the representative agent's preferences. By adding 'habits' to the utility function, these authors provide alternative models of preferences in which the representative agent's marginal utility is highly sensitive to movements in consumption. The additional volatility in marginal utility that occurs in habit formation preferences increases the covariance of the marginal utility of consumption with the stochastic discount factor and helps to explain a large equity premium.

In Constantinides' (1990) paper, habits are determined by the previous consumption of a representative agent whereas Abel, (1990), assumes that there are many

\footnotetext{
${ }^{4}$ This is the special case of RINCE preferences (Farmer, 1990) for which the elasticity of substitution is unity. RINCE is an acronym for RIsk Neutrality Constant Elasticity of substitution.
} 
identical representative agents, each of whom cares about what other agents consumed in the past. Although these papers can account for a large equity premium, they do it at the cost of producing a riskless rate that is counterfactually volatile. Campbell and Cochrane (1999) solve this problem by using the data to determine how the past consumption of other agents, influences marginal utility.

In a separate literature, Rietz (1988), and Barro (2006), argue that there is a small but significant probability of occasional large disasters. Even if a disaster has not occurred in sample, the possibility that it might occur in the future will cause the representative agent to appear excessively cautious. But although the Barro-Reitz model can explain the equity premium, it cannot explain the excess volatility of stock market returns.

Bansal and Yaron (2004) have shown that persistence of the dividend growth rate, and time varying volatility of asset returns, are important elements of an explanation of a high equity premium. In separate but related work, both Gabaix (2008, 2012) and Wachter (2013) modify the rare disaster model by assuming that the probability of rare disasters varies over time. Using that assumption, they are able to explain volatility in the stochastic discount factor in a model that also has a high equity premium. But although the rare disaster explanation is promising, it is not uncontroversial, and Julliard and Ghosh (2012) have argued that rare disasters do not occur often enough in the data for the hypothesis to be plausible.

An alternative explanation for excess volatility was developed by Farmer, Nourry, and Venditti (2012). Building on Farmer (2002a,b), they constructed a two-agent version of Blanchard's (1985) perpetual youth model, and they showed that it generates a volatile stochastic discount factor as a consequence of non-fundamental shocks. ${ }^{5}$ But although their model succeeds in generating large and volatile fluctuations in the stochastic discount factor, it cannot explain why there is a large equity premium or a large term premium.

The current paper is most closely related to a literature that combines incomplete participation with heterogenous agents and incomplete markets. Guvenen (2009) constructs a production economy with all three of these features that he solves computationally. Kubler and Schmedders (2011) construct a heterogenous agent overlapping generations model with sequentially complete markets. By dropping the rational

\footnotetext{
${ }^{5}$ Cass and Shell (1983) refer to non-fundamental shocks as 'sunspots'. They showed that sunspots can alter the allocations of consumption goods across agents, even when there is a complete set of asset markets. Farmer, Nourry, and Venditti (2012) extended the model of Cass and Shell to a calibrated example with long-lived agents.
} 
expectations assumption, they are able to generate substantial asset price volatility. Constantinides and Duffie (1996) exploit cross-section heterogeneity of the income process and they show that uninsurable income risk across consumers can potentially explain any observed process for asset prices. However, Storesleten and Yaron (2007) argue that the ability of the Constantinides-Duffie model to explain the equity premium, is considerably reduced, once one allows for realistic population demographics and the possibility of capital accumulation.

Vissing-Jorgenson (2002) has argued that the elasticity of substitution of stock holders is lower than that of bond holders and Vissing-Jorgenson and Attanasio (2003) use that fact to offer a partial resolution of the equity premium puzzle. My work exploits that same idea. The equity premium depends on the covariance of the stochastic discount factor with the consumption of asset holders. And since, in my model, there is more than one type of agent, the consumption growth of individuals can be volatile even when the consumption growth of aggregate consumption is not. Although aggregate consumption in my model is constant, the consumption growth of individual agents displays substantial variation.

I will argue, in this paper, that a large part of the equity premium puzzle is a puzzle over the term premium, not the risk premium. I will show, that if the stochastic discount factor is sufficiently volatile, the value of leveraged equity in a company will offer a high and volatile return, even if the dividend payment offered by the firm is safe.

\section{Risk Premia ANd Term Premia}

Macroeconomists typically assume that households maximize the expected discounted present value of a time-separable von-Neumann Morgenstern (VNM) utility function. In this paper, I use a more general class of recursive preferences developed by Kreps and Porteus (1978, 1979), Epstein and Zin (1991, 1989) and Farmer (1990). These preferences separate the coefficient of relative risk aversion from the intertemporal elasticity of substitution: two concepts that are indistinguishable in the special case of expected utility. ${ }^{6}$

Recursive utilities are generated by an aggregator function $W(x, y)$, where

$$
U_{t}=W\left(C_{t}, E_{t}\left[U_{t+1}\right]\right)
$$

\footnotetext{
${ }^{6}$ Recursive preferences for finite horizons are due to Kreps and Porteus $(1978,1979)$. Epstein and Zin $(1991,1989)$ generalized their results and extended them to the infinite horizon case. The risk neutral example used here was first studied by Farmer (1990).
} 
Expected utility is the special case of recursive preferences in which the function $W(x, y)$ is linear in $y$ and, in this case, utility can be expressed recursively as

$$
U_{t}=V\left(C_{t}\right)+\beta E_{t}\left[U_{t+1}\right]
$$

where $V(\cdot)$ is an increasing concave function and $\beta$ is the agent's discount factor.

Here, I use a special case of recursive preferences, RINCE preferences, (Farmer, 1990), in which agents are indifferent to one step ahead risk and in which they display a constant intertemporal elasticity of substitution. ${ }^{7}$ RINCE preferences are generated by the aggregator

$$
\log \left(U_{t}\right)=\log \left(C_{t}\right)+\beta \log \left(E_{t}\left[U_{t+1}\right]\right) .
$$

Importantly, these preferences admit closed form solutions to intertemporal problems with incomplete asset markets. Agents with RINCE preferences will tolerate very large swings in one-step ahead consumption, but they become risk averse at longer horizons.

One might conjecture that, if agents are indifferent to one-step-ahead risk, that the model has no hope of explaining an equity premium of $6 \%$. That conjecture is false since agents with RINCE preferences do care about the covariance of asset returns with the marginal utility of consumption. And since the term premium and risk premium are confounded in much of the empirical literature, a model with a substantial term premium can go a long way to towards explaining the observed equity premium puzzle.

\section{My LIFECyCle MODEL}

In this section I will construct a lifecycle model in which agents of different generations have different savings rates and I will explain how this model can account for both a high term premium and a volatile stochastic discount factor. Unlike the habit formation models of Constantinides (1990) and Abel (1990), my model generates a smooth path for the safe rate of interest.

My model builds on Gertler (1999), who studied an economy with two generations. Following Blanchard (1985), Gertler constructs an economy where agents die each period with an age-invariant probability. He extends Blanchard's framework to allow for a stochastic transition from youth to old age. I use that same idea.

In my model there are two generations of agents. Workers earn a constant endowment stream of 1 unit and retirees earn nothing, and like Gertler (1999), I assume

\footnotetext{
${ }^{7}$ RINCE is an acronym for RIsk Neutral, Constant Elasticity of substitution (Farmer, 1990).
} 
that the transition from work to retirement is stochastic. Gertler uses RINCE preferences to find a solution to a problem where agents cannot insure against the event of retirement. I modify the Gertler economy by allowing for an insurance market over the observable random event of retirement.

Three features of my model account for its success in solving the two asset pricing puzzles. The first feature is that shocks are unbounded above. That allows me to construct equilibria in which the stochastic discount factor is extremely volatile. ${ }^{8}$ The second feature is that the lower bound on non-fundamental shocks is state dependent. That provides additional volatility to the stochastic discount factor and generates time varying return volatility, a property that also characterizes the time series data. The third feature, is that agents are indifferent to one-step ahead consumption risk. By exploiting these three features, my lifecycle model is able to explain both excess volatility and a considerable part of the equity premium with a parsimonious model in which the parameters of the model are pinned down by population demographics.

\section{Asset Pricing in a Lifecycle Model}

In this section, I will explain how asset pricing in a lifecycle model differs from asset pricing in a representative agent model. The main difference is that the expression for the pricing kernel no longer depends on aggregate consumption growth. Instead, it depends on the division of resources between workers and retirees. That fact allows me to construct equilibria in a lifecycle model in which asset prices are volatile, even when aggregate consumption growth is not.

Consider an asset that sells for price $p$ and pays 1 unit of a unique consumption good with probability $\pi_{1}$ and 0 units in all future periods, with probability $\left(1-\pi_{1}\right)$. This asset has three interpretations.

First, it is the human wealth of a worker who retires with probability $\left(1-\pi_{1}\right)$. Second, it is a bond that pays a coupon that decays at rate $\pi_{1}$, a theoretical construct suggested by Woodford (2001) to model long duration bonds. ${ }^{9}$ Third, it is a claim to an unleveraged firm that has a dividend stream of 1 unit with probability $\pi_{1}$ and nothing in all future periods with probability $\left(1-\pi_{1}\right)$.

Let $Q^{\prime}$ represent the price for delivery of a consumption good next period in state $s^{\prime}$, divided by the conditional probability that this state will occur. The price of the

\footnotetext{
${ }^{8}$ This differs from previous work by Farmer, Nourry, and Venditti (2012) where non-fundamental shocks have bounded support.

${ }^{9} \mathrm{~A}$ Woodford bond has a duration of $1 /\left(1-\pi_{1}\right)$ years. By choosing this number appropriately, a Woodford bond can be used to find a tractable formula for the price of a bond of any desired maturity.
} 
asset $p$ is determined by the equation,

$$
p=1+E\left[\pi_{1} Q^{\prime} p^{\prime}\right]
$$

Because I assume that the aggregate endowment is constant, this is a model with no fundamental aggregate uncertainty. In a representative agent model, the assumption that there is no fundamental uncertainty would imply that $Q^{\prime}$ is constant and equal to $\beta$. In the lifecycle model studied here, I will show that $Q^{\prime}$ can be expressed as a rational polynomial in asset prices

$$
Q^{\prime}=\frac{a_{0}+a_{1} p}{b_{0}+b_{1} p^{\prime}}
$$

where the parameters $a_{0}, a_{1}, b_{0}$ and $b_{1}$ are functions of the rate of time preference, the expected duration of a person's working life, and the expected duration of his time spent in retirement. Because agents are indifferent to one-period return risk, the marginal rate of substitution will not be equated, state by state, to the pricing kernel. But because agents care about when they consume, they do care about the covariance of $Q^{\prime}$ with human wealth. That fact explains why the model is able to deliver a term premium for a long lived asset over a one period bond.

\section{Demographics}

This section explains the assumptions I make about population demographics. I assume a pure exchange economy that consists of a measure $n_{1}$ of workers and a measure $n_{2}$ of retirees. Population is constant and equal to one,

$$
n_{1}+n_{2}=1
$$

Time is discrete and retirement and death are modeled as stochastic events. Each period a worker has a probability $\pi_{1}$, of remaining active and a probability $1-\pi_{1}$ of retiring. A retired worker has a probability $\pi_{2}$ of surviving for an extra period and a probability $1-\pi_{2}$ of dying. ${ }^{10}$

I assume that the number of deaths equals the number of births and the measures of workers and retirees are constant. Since $n_{1}\left(1-\pi_{1}\right)$ workers retire each period there must be $n_{1}\left(1-\pi_{1}\right)$ births to replace them. And since I assume a stationary population, the measure of births must equal the measure of deaths,

$$
\left(1-\pi_{1}\right) n_{1}=\left(1-\pi_{2}\right) n_{2}
$$

\footnotetext{
${ }^{10} \mathrm{I}$ assume for simplicity that workers retire before dying although relaxing that assumption is not difficult and does not materially alter the main results.
} 
Using the assumption that the total population size is one, equations (6) and (7) imply that the stationary measures of workers and retirees are given by the expressions,

$$
n_{1}=\frac{1-\pi_{2}}{2-\pi_{1}-\pi_{2}}, \quad n_{2}=\frac{1-\pi_{1}}{2-\pi_{1}-\pi_{2}} .
$$

Since the population of each group is stationary, the inflow of new workers must equal the inflow of new retirees, also equal to the number of deaths. Using the symbol $\lambda$ to represent this number, we may rewrite the expressions from Equation (7) as follows,

$$
\lambda=\frac{\left(1-\pi_{2}\right)\left(1-\pi_{1}\right)}{2-\pi_{1}-\pi_{2}} .
$$

\section{Pensions and Annuities}

In this section, I explain the institutions that insure workers against the event of retirement and that provide annuities to retirees to support their consumption in old age.

Each worker is endowed with one unit of the endowment in every period in which he remains active. Retirees are endowed with zero units of the endowment and they must live off the assets acquired during their working life. These assumptions provide a demand for two specialized assets; pensions and annuities. I assume that workers can purchase actuarially fair pensions and that retirees can purchase actuarially fair annuities. Consider first, the market for pensions.

There is a large number of competitive risk-neutral pension funds that invest in a riskless security that costs $\bar{Q}$ units at date $t$ and pays 1 unit at date $t+1$. Each pension fund offers two securities for sale to workers. A type 1 security sells for price $p_{1}$ and pays 1 unit in the subsequent period if the worker remains active, and nothing, if he retires. A type 2 security sells for price $p_{2}$ and pays nothing next period if the worker remains active, and 1 unit, if he retires. By purchasing a portfolio of these two securities, the worker can provide for any chosen allocation of his future wealth between the states of employment and retirement. Importantly, I assume that the event of retirement is stochastic and cannot be influenced by any decision taken by the worker.

The assumption that this pension scheme is actuarially fair implies that

$$
p_{1}=\pi_{1} Q, \quad p_{2}=\left(1-\pi_{1}\right) Q
$$

There is a similar scheme for retirees. A retired person pays $\pi_{2} Q$ units at date $t$ for a security that pays 1 unit at date $t+1$, if he remains alive, and nothing, if he dies. In the event of death, the assets of the retiree are returned to the annuities company. 


\section{Assumptions about the Financial Markets}

In the lifecycle model I construct in this paper, I will allow for a complete set of Arrow securities and I will use the notation $\alpha(s)$, or just $\alpha$, to refer to a type $s$ Arrow security. The security $\alpha(s)$ pays 1 unit of the commodity, if and only if state $s$ occurs.

I will show, in Proposition 1, that the assumption that agents have RINCE preferences implies that the division of Arrow securities between workers and retirees is indeterminate, and hence, the equilibrium I describe would be supported even if the asset markets were incomplete. I view this assumption as a convenient short-cut to finding the closed form solution to an incomplete markets problem. ${ }^{11}$

Armed with this notation, I will introduce three concepts of wealth, and I will use these concepts to construct the period budget constraints of a worker and a retiree. These three concepts are the total wealth of a worker that I call $W$, the human wealth of a worker, that I call $h$, and the financial assets of a worker or retiree that I call $\alpha_{i}$ where I use a subscript 1 to denote a worker and 2 to denote a retiree. Using this notation, the wealth of a worker is given in Equation (11) as the sum of financial assets, $\alpha_{1}$ and human wealth, $h$,

$$
W=\alpha_{1}+h .
$$

There is no subscript on $W$ or $h$ because I use these terms exclusively to refer to workers. Retirees have no human wealth and, as a consequence, their wealth is equal to their net financial assets, $\alpha_{2}$.

Human wealth is defined recursively by the following functional equation,

$$
h=1+\pi_{1} E\left[Q^{\prime} h^{\prime}\right] .
$$

This is Equation (5) from Section 5. The human wealth of a worker is equal to the discounted stream of endowments, discounted at price $Q^{\prime} / \psi$, where $Q^{\prime}$ is the Arrow security price in state $s$ and $\psi$ is the probability that state $s$ occurs. In a representative agent economy, this equation would be solved forward after replacing

\footnotetext{
${ }^{11}$ The assumption of RINCE preferences allows me to find a closed form for the decision rules of the agents. Although I assume that markets are complete, that assumption is made for notational convenience, and the model with incomplete markets has the same equilibria. I conjecture that a model with risk aversion and incomplete markets will display a similar solution to the explicit equilibrium that I derive here. That conjecture follows from the work of Balasko and Cass (1989) who have shown that sunspot fluctuations occur generically in models with incomplete asset markets.
} 
$Q^{\prime}$ by the constant discount factor, $\beta$, to find an expression for $h$ as the discounted sum of all expected future income.

I will show, in this model, that $Q^{\prime}$ can be expressed, in equilibrium, as a function of $h$ and $h^{\prime}$. Replacing $Q^{\prime}$ by this function in Equation (12) leads to an expression that can be solved backwards to find $h^{\prime}$ as a function of $h$. And because the steady state of this equation is stable, there exist equilibria in which stochastic sunspot shocks reallocate resources between workers and retirees.

\section{Budget Constraints of Workers And Retirees}

In this section, I will use the definitions of wealth, human wealth and financial assets to write down the budget constraints of a worker and a retiree.

Consider first, the budget constraint of a representative worker.

$$
\alpha_{1}+1-C_{1}=\pi_{1} E\left[\alpha_{1}^{\prime} Q^{\prime}\right]+\left(1-\pi_{1}\right) E\left[\alpha_{2}^{0 \prime} Q^{\prime}\right] .
$$

The worker enters the period holding net financial assets $\alpha_{1}$. He receives an endowment of 1 unit and he chooses to consume $C_{1}$ units of the consumption good. That explains the left side of Equation (13).

The first term on the right side, $\pi_{1} E\left[\alpha_{1}^{\prime} Q^{\prime}\right]$, is the worker's purchases of Arrow securities, contingent on remaining a worker. The second term on the right side of Equation (13), $\left(1-\pi_{1}\right) E\left[\alpha_{2}^{0 \prime} Q^{\prime}\right]$, is the workers purchase of pension assets contingent on retirement. In the event that the worker retires in period $t+1$, he receives the

retirement assets $\alpha_{2}^{0 \prime}$. I use the subscript 2 because, if he retires, the worker becomes a retiree.

A similar expression to Equation (13), holds for retirees,

$$
\alpha_{2}-C_{2}=\pi_{2} E\left[\alpha_{2}^{\prime} Q^{\prime}\right]
$$

The retiree has no endowment income and his wealth is equal to his financial assets $\alpha_{2}$. His consumption is $C_{2}$ and his accumulation of contingent assets is equal to $\pi_{2} E\left[\alpha_{2}^{\prime} Q^{\prime}\left(S^{\prime}\right)\right]$. I now turn to the behavior of an agent at different stages of life.

\section{Decision Rules}

This section derives the decision rules that would be followed by a worker and a retiree who maximize utility subject to the budget constraints outlined in Section IX. I assume that utility is recursive, and described by the functions,

$$
\log \left(U_{1, t}\right)=\log \left(C_{t}\right)+\beta \pi_{1} \log \left(E_{t}\left[U_{1, t+1}\right]\right),
$$


for workers and

$$
\log \left(U_{2, t}\right)=\log \left(C_{t}\right)+\beta \pi_{2} \log \left(E_{t}\left[U_{2, t+1}\right]\right),
$$

for retirees. The parameter $\beta$ is the common discount factor, $\left(1-\pi_{1}\right)$ is the probability that a worker will retire and $\left(1-\pi_{2}\right)$ is the probability that a retiree will die. The assumption of RINCE preferences leads to decision rules that are linear in wealth. The form of these rules is summarized in Proposition 1.

Proposition 1. The solution to the workers' and the retirees' decision problems are represented by a set of linear decisions rules described by equations (17)-(19):

$$
\begin{aligned}
C_{1} & =A^{-1} W, \\
Q^{\prime} \alpha_{2}^{0} & =\frac{1-\beta \pi_{1}}{1-\beta \pi_{2}} W, \\
C_{2} & =B^{-1} \alpha_{2},
\end{aligned}
$$

where $A$ and $B$ are positive real numbers, defined by the expressions

$$
A=\frac{\left(1-\beta \pi_{2}\right)+\left(1-\pi_{1}\right) \beta}{\left(1-\beta \pi_{1}\right)\left(1-\beta \pi_{2}\right)}, \quad B=\frac{1}{1-\beta \pi_{2}},
$$

where

$$
0<B<A
$$

Workers and retirees are indifferent to any asset allocation for which

$$
\frac{1}{C_{1}}=\frac{\beta}{E\left[Q^{\prime} C_{1}^{\prime}\right]}, \quad \text { and } \frac{1}{C_{2}}=\frac{\beta}{E\left[Q^{\prime} C_{2}^{\prime}\right]} .
$$

Proof. See Appendix A.

Equations (17) and (18) are the decision rules for a young agent. Equation (17) instructs him to consume a fraction $A^{-1}$ of his wealth in every state and Equation (18) provides the rule for how his saving is to be allocated between pension assets and non pension assets. Equation (19) is the decision rule for a retiree.

Equations (22) provide restrictions on the set of equilibrium pricing kernels. They are the only restrictions that follow from the first order conditions for choice of future consumption. Even though workers and retirees have the option of determining the allocation of consumption across states, the linearity of the value function in expected wealth implies that both types of agents will be indifferent to one-step ahead consumption risk. Notice however, that agents are not indifferent to the covariance of the pricing kernel with consumption. That fact generates a term premium for long lived assets. 


\section{Equilibrium}

In this section I will characterize an equilibrium as the solution to a functional equation in a single state variable, human wealth. The proof proceeds by establishing two lemmas. First I show how the consumption of the young depends on human wealth; then I establish that the stochastic discount factor is a rational polynomial in $h$ and $h^{\prime}$.

To establish the first lemma, I use the solution to the decision problems from Proposition 1 together with the asset market clearing and goods market clearing conditions.

Lemma 1. Define the sets $H \equiv[B, A]$ and $\bar{C}=[0,1]$. There exists an increasing affine function $\phi(\cdot): H \rightarrow \bar{C}$ such that the aggregate consumption of workers, $C_{1}$, is given by the expression,

$$
C_{1}=\phi(h) \equiv \frac{h-B}{A-B} .
$$

Further, the aggregate consumption of retirees, $C_{2}$, is given by

$$
C_{2}=1-\phi(h) \equiv \frac{A-h}{A-B} .
$$

In period 0 , human wealth is pinned down by the initial condition

$$
h_{0}=\frac{(A-B)}{B} \bar{\alpha}_{10}+1,
$$

where $\bar{\alpha}_{10}$ is the net financial assets of workers in period 0 .

Proof. See Appendix B.

Next, I turn to the pricing kernel, $Q^{\prime}$. To obtain an expression for this term, I use the first order condition of a worker, together with the asset and goods market clearing conditions.

Lemma 2. There exists a function $\zeta(\cdot): H \times H \rightarrow R_{+}$such that the stochastic discount factor, $Q^{\prime}$ given by the expression

$$
Q^{\prime}=\zeta\left(h, h^{\prime}\right) \equiv \frac{D_{1}(h-B)}{D_{2} h^{\prime}-A B},
$$

is a valid equilibrium pricing kernel. The parameters $D_{1}$ and $D_{2}$ are defined as,

$$
D_{1}=A \beta \pi_{1}, \quad D_{2}=A(1-\lambda)+B \lambda,
$$

and $\lambda$ is the measure of newborns from Equation (9).

Proof. See Appendix C 
Using lemmas 1 and 2, I am ready to provide a characterization of competitive equilibria for this economy. From (12) we have

$$
h-1=E\left[\pi_{1} Q^{\prime} h^{\prime}\right] .
$$

Replacing $Q^{\prime}$ in (28) from (26) gives

$$
h-1=E\left\{\pi_{1} \frac{D_{1}(h-B)}{D_{2} h^{\prime}-A B} h^{\prime}\right\} .
$$

Equation (29) is a difference equation in $h^{\prime}$ that characterizes sequences $\{h\}$ which satisfy the goods and asset market clearing conditions,

$$
C_{1}+C_{2}=1, \quad \alpha_{1}+\alpha_{2}=0
$$

and the optimal decision rules, (17) - (19). Any sequence $\{h\}$ that satisfies this equation, together with the feasibility conditions that $Q^{\prime}>0$ and $C_{1} \in \bar{C}$, and the initial condition, $\alpha_{1}(0)=\bar{\alpha}_{1}$, completely characterizes a competitive equilibrium.

One equilibrium sequence is generated by non-stochastic solutions to the implicit difference equation

$$
h-1=\pi_{1} \frac{D_{1}(h-B)}{D_{2} h^{\prime}-A B} h^{\prime}, \quad h_{0}=\frac{(A-B)}{B} \bar{\alpha}_{10}+1 .
$$

But this is not the only equilibrium in this economy. Because of the fact that agents are indifferent as to the allocation of consumption across states, there are also solutions to this equation in which non-fundamental shocks influences outcomes. That idea is captured in Proposition 2.

Proposition 2. Define the set $\bar{H} \equiv\left[B_{1}, A\right]$ where

$$
B_{1}=\frac{A B}{(1-\lambda) A+\lambda B} .
$$

There exists a sequence of non-fundamental random variables $\left\{s^{\prime}\right\}$, a function $\bar{S}_{1}$ : $\bar{H} \rightarrow[0,1]$, a set $\bar{D}$, and pair of functions $g: \bar{D} \rightarrow \bar{H}, \psi: \bar{D} \rightarrow R_{+}$such that the sequence $\{h\}$ given by the difference equation

$$
h^{\prime}=g\left(h, s^{\prime}\right)
$$

with initial condition

$$
h_{0}=\bar{h}_{0} \in \bar{H}
$$

defines a competitive equilibrium. The pricing kernel is given by the expression

$$
Q^{\prime}=\psi\left(h, s^{\prime}\right)
$$


The functions $g(\cdot)$ and $\psi(\cdot)$ are given by the expressions

$$
\begin{gathered}
g\left(h, s^{\prime}\right)=\frac{A B(h-1) s^{\prime}}{D_{2}(h-1) s^{\prime}-\pi_{1} D_{1}(h-B)}, \\
\psi\left(h, s^{\prime}\right)=\frac{1}{A B \pi_{1}}\left[D_{2}(h-1) s^{\prime}-\pi_{1} D_{1}(h-B)\right] .
\end{gathered}
$$

The random variables $\left\{s^{\prime}\right\}$ are drawn from a set of distributions which satisfy the following properties. First, the conditional mean of $s^{\prime}$ is equal to 1 ;

$$
E\left[s^{\prime} \mid h\right]=1
$$

Second, the support of $s^{\prime}$ is unbounded above and has a lower bound $S_{1}(h)$,

$$
s \in \bar{S}(h) \equiv\left[\bar{S}_{1}(h), \infty\right],
$$

where $S_{1}(h)$ is the unique solution to the affine equation

$$
g\left(h, \bar{S}_{1}(h)\right)=A \text {. }
$$

The set $\bar{D}$ is defined by the condition

$$
\bar{D} \equiv\left\{x \in R_{+}^{2} \mid x_{1} \in \bar{H}, x_{2} \in\left[\bar{S}_{1}\left(x_{1}\right), \infty\right)\right\}
$$

Proof. See Appendix D.

The function $g\left(h, s^{\prime}\right)$ describes the evolution of human wealth from one period to the next. The domain of this function is the set $\bar{D}$. The first component of $\bar{D}$ is $h$ which must be in the support of the invariant distribution. The second component of $\bar{D}$ is $s^{\prime}$ which is a random variable with a support that is unbounded above, and bounded below by a number that depends on $h$.

\section{The Properties of Shocks}

This section is technical and can be omitted without losing the flow of my argument. I show how to construct the set $\bar{D}$ and I explain why the support of the shocks is unbounded above and why the lower bound of the shock distribution depends on $h$. These important features of the model enable it to explain excessive asset price volatility and a large equity premium.

Figure 1 illustrates the properties of the function $g\left(h, s^{\prime}\right)-h$ for three different realizations of the shock $s^{\prime}$. This function plots the change in $h$ between dates $t$ and $t+1$ on the vertical axis against the value of $h$ on the horizontal axis. The feasible set

is $[B, A]$. When $h=B$, the retirees consume the entire endowment and when $h=A$, the workers consume everything 


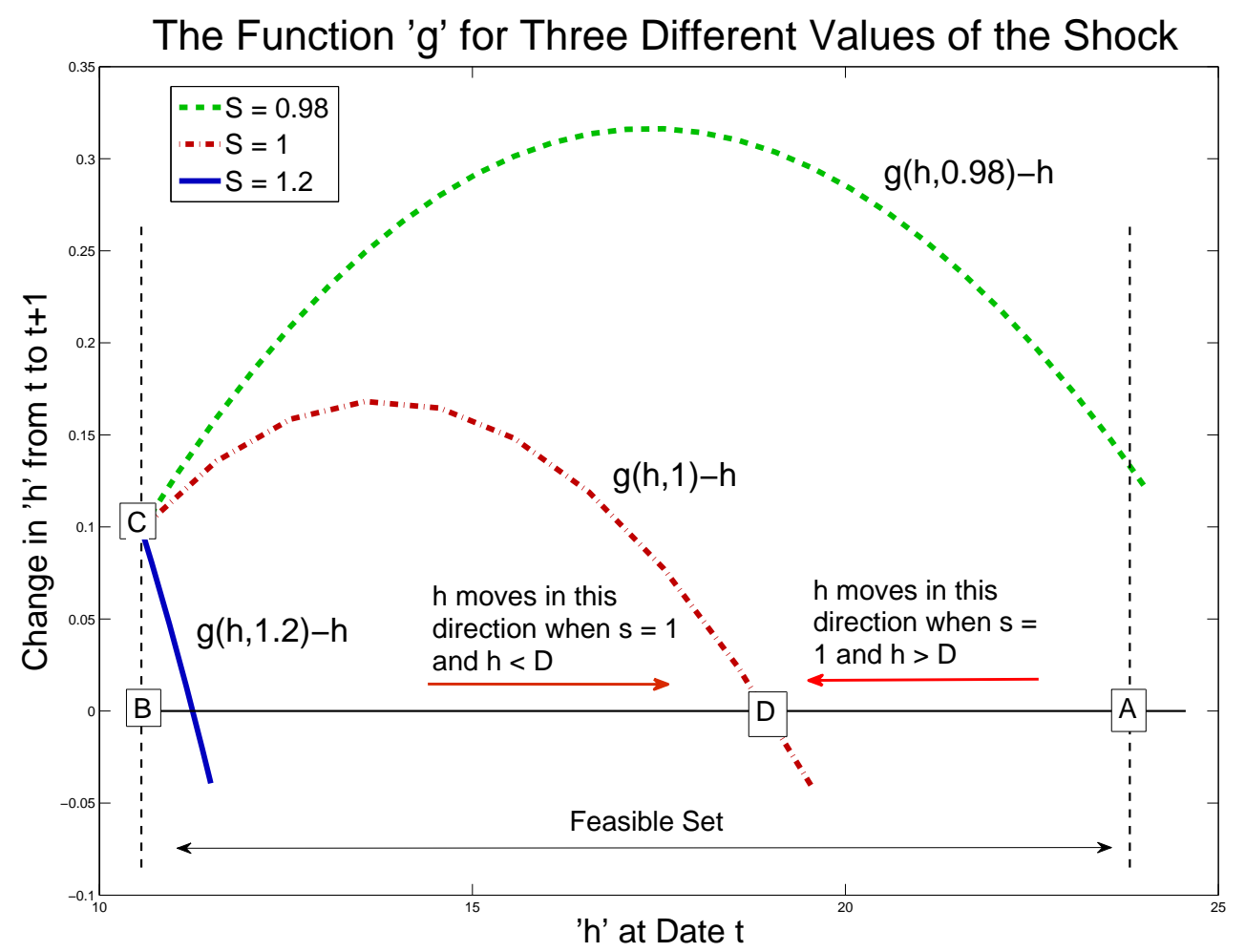

Figure 1: The Evolution Equation for Human Wealth

The solid blue line represents the function $g\left(h, s^{\prime}\right)-h$ for a relatively large value of $s^{\prime}$, equal to 1.2. The dashed green line is the function $g\left(h, s^{\prime}\right)-h$ for a small value of $s^{\prime}$, equal to 0.98; and the dash-dot red line is the value of the this function when the shock is equal to its mean value of 1 . The figure illustrates that, if the economy were to be hit by a constant sequence of shocks, all equal to 1 , that $h$ would converge to point $D$.

The fact that the shock distribution is unbounded above follows from equation (36) which I repeat below

$$
g\left(h, s^{\prime}\right)=\frac{A B(h-1) s^{\prime}}{D_{2}(h-1) s^{\prime}-\pi_{1} D_{1}(h-B)} .
$$

Dividing the numerator and denominator of Equation (42) by $s^{\prime}$ and taking the limit as $s^{\prime} \rightarrow \infty$, it follows that $g\left(h, s^{\prime}\right)$ converges to a number, $B_{1}$ as $s^{\prime}$ converges to $\infty$ where,

$$
B_{1}=\frac{A B}{D_{2}} \equiv \frac{A B}{(1-\lambda) A+\lambda B} .
$$

Notice that the number $B_{1}$ is greater than $B$ and less than $A$ and hence $s^{\prime}=\infty$ is feasible and the support of feasible shocks is unbounded above. 
What about a lower bound? Inspection of Equation (42) reveals that small shocks can cause $h^{\prime}$ to become larger than the maximum feasible value of $A$ and it follows from that fact that the set of feasible shocks is bounded below. But the smallest feasible shock is not state independent; it depends on $h$.

Finding a Lower Bound for the Support of $s$

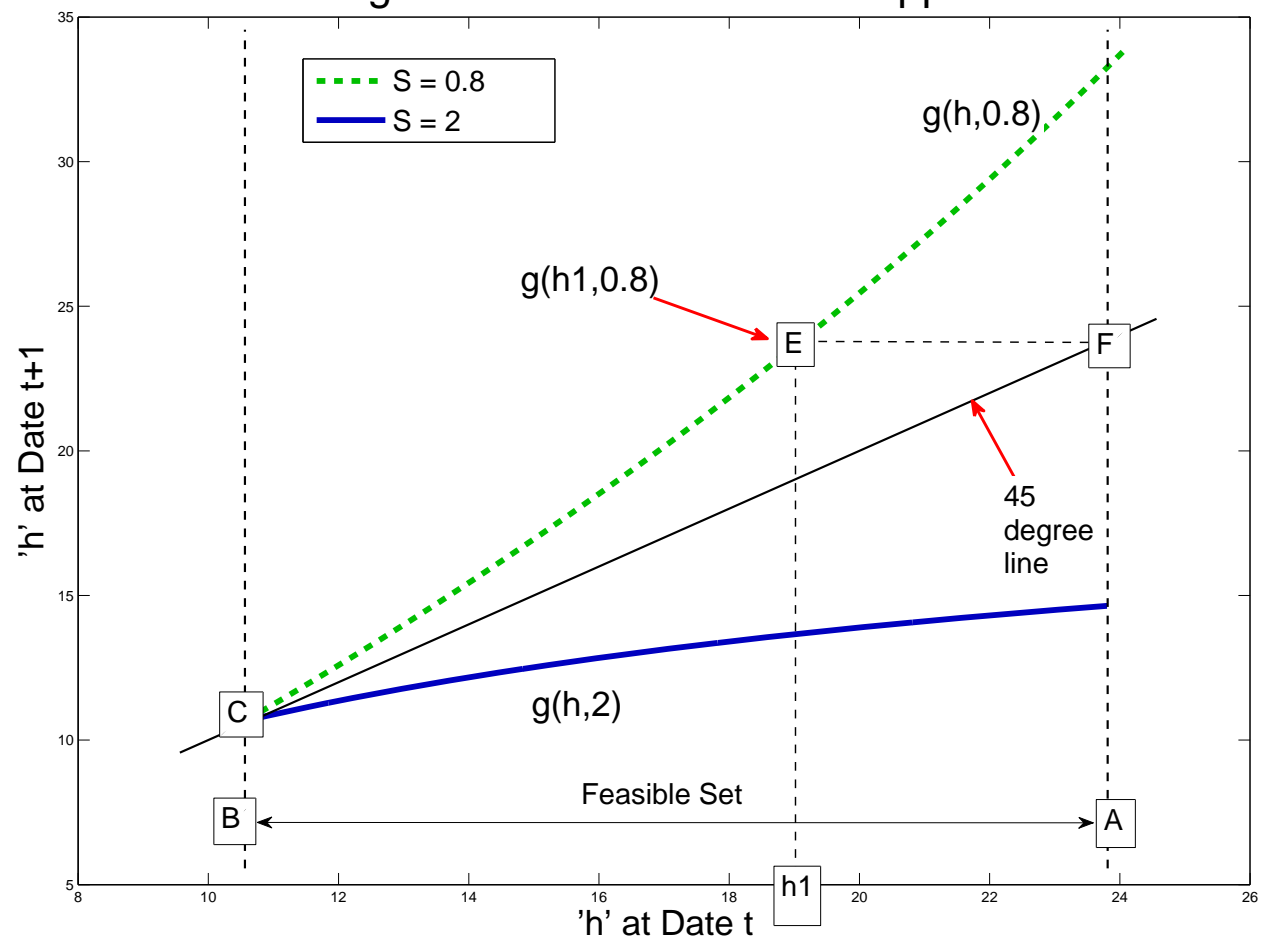

Figure 2: The Support of the Shock Distribution

Figure 2 plots $h^{\prime}$ on the vertical axis and $h$ on the horizontal axis. The figure illustrates the function $g\left(h, s^{\prime}\right)$ for two different values of the shock, $s^{\prime}=0.8$ and $s^{\prime}=2$. When the economy is hit by a large shock, next period's human capital will always remain feasible. That fact is illustrated by the solid blue curve which shows what happens to next period's human capital when the shock $s^{\prime}$, is equal to 2 .

When the economy is hit by a small shock, next period's human capital will remain feasible if $h$ is small, but not if $h$ is large. That is illustrated on Figure 2 by the dashed green line which represents the function $g\left(h, s^{\prime}\right)$ for a value of $s^{\prime}$ equal to 0.8. The figure shows that for values of $h$ less than $h_{1}, s^{\prime}$ is feasible since $g(h, 0.8)$ is feasible. But if $h$ is greater than $h_{1}$ then $s^{\prime}$ equal to 0.8 is not feasible since $g(h, 0.8)$ will be bigger than $A$.

To ensure that $h^{\prime}$ remains feasible for all $s^{\prime} \in \bar{S}$, we can make the support of $s^{\prime}$ conditional on $h$ by defining a function $\bar{S}_{1}(h)$ such that $g\left(h, \bar{S}_{1}(h)\right)=A$. This 
function is illustrated on Figure 2. The figure shows that $\bar{S}_{1}\left(h_{1}\right)=0.8$ since $s^{\prime}=0.8$ maps $h_{1}$ to $A$, the boundary of the feasible set.

What else do we know about feasible values of $s^{\prime}$ ? Not much since economic theory does not place strong restrictions on the distribution of $s^{\prime}$. It must obey the property that

$$
E\left(s^{\prime} \mid h\right)=1
$$

and its support, $\bar{S}$, must have the property that

$$
g(h, \bar{S}) \subset \bar{H} \text { for all } h \in \bar{H} .
$$

In the simulation results, reported below, I used a log normal distribution for $s^{\prime}-\bar{S}_{1}(h)$. Specifically, I assumed that

$$
s^{\prime} \sim \exp \left(x \sigma-\frac{\sigma^{2}}{2}+\log \left(1-\bar{S}_{1}(h)\right)\right)+S_{1}(h),
$$

where $x$ is a standard normal random variable and $\sigma$ is a parameter that controls the standard deviation of $s^{\prime}$. It follows from the properties of the lognormal distribution that $E\left(s^{\prime}\right)=1$ and that the support of $s^{\prime}$ is $\bar{S} \equiv\left[\bar{S}_{1}(h), \infty\right]$.

Is it reasonable to impose a conditional bound on the support of sunspot shocks? I think so. The assumption that shocks have a larger support when $h$ is small, implies that the risky rate will be more volatile when asset prices are low than when asset prices are high. In other words, the model displays conditional heteroskedasticity, a feature that is known to characterize real world asset data.

\section{Using a Simple Lifecycle Model to Explain the Data}

The lifecycle model I have constructed is extremely simple. There is no fundamental uncertainty and no production, and, there is a complete set of asset markets and two generations of agents. Agents have rational expectations and a simple generalization of logarithmic preferences. Nevertheless, the model captures the two anomalies of asset pricing that I referred to in the introduction: it produces volatile asset prices and a substantial term premium. To illustrate these features of the model, I calibrated it in the way described in Table 1.

\begin{tabular}{lll|ll} 
Table 1 & Value & \multicolumn{2}{|c}{ Implied Value } \\
\hline \hline$\beta$ & Time preference factor & 0.97 & & \\
$\pi_{1}$ & Pr. of remaining a worker & 0.9778 & Expected Working Life & 45 years \\
$\pi_{2}$ & Pr. of remaining retired & 0.9333 & Expected Retirement & 15 years \\
$\sigma$ & St. Deviation of Shock & 0.5 & & \\
\hline \hline
\end{tabular}


Figure 3 compares simulated data on the left two panels with actual U.S. data on the right. The simulated data represents one draw of 60 years using the parameter values from Table 1. The top left panel plots the yield to maturity on a long bond (the dashed red line) and the risk free rate (the solid blue line). The gross yield to maturity for a long bond in simulated data was calculated as

$$
R^{L}=\pi_{1} \frac{h}{h-1},
$$

and the gross short rate was calculated as

$$
R^{s}=\frac{1}{E\left(Q^{\prime}\right)}
$$

The gross yield to maturity is the annualized return from purchasing a bond at price $h$ and holding it to maturity. The gross short rate is the inverse of the sum of the Arrow security prices.

The parameter $\pi_{1}$ enters Equation (46), because the coupon on the bond decays at rate $\pi_{1}$. I chose this parameter to equal the survival probability of a worker and its value of 0.9778 implies an expected life of 45 . Hence, the implied maturity of a long bond in this model is also 45 years and the yield to maturity, $r^{L}$, is the yield on a 45 year bond purchased at price $h$. For the simulated data series depicted in Figure 3, the average yield on a long bond was $2.49 \%$ and the average return to a short term asset was equal to $1.43 \%$ yielding a sample term premium of $1.1 \%$.

The top right panel of Figure 3 plots the three month treasury bill rate against the yield to maturity of a long term government bond in time series data. The data are monthly at annualized rates and they start in 1960 and end in 2000, when the long bond data were discontinued. This sample includes the great inflation of the late $1970 s$ and early $1980 s$ and I have not attempted to correct either series for inflation. ${ }^{12}$ The mean of the long bond yield in these data is $7.2 \%$ and the mean of the Tbill rate is $6 \%$ giving a term premium of $1.2 \%$.

To compute the risky return on a leveraged claim, I first computed the unleveraged gross risky rate, $R^{R}$ as

$$
R^{R}=\frac{\pi_{1} h^{\prime}}{h-1}
$$

\footnotetext{
${ }^{12}$ An inflation premium will be included in both series and, although these premia need not be identical, it is not obvious how the two series should be adjusted to account for these differences. That caveat should be taken into account when comparing the term premium from the model with the term premium in the data.
} 
The numerator of the risky rate $R^{R}$, is $\pi_{1} h^{\prime}$ as opposed to the numerator of the long bond yield, which is $\pi_{1} h$. This reflects the assumption that the long asset is purchased at date $t$ for price $h$ and sold one year later for price $h^{\prime}$.
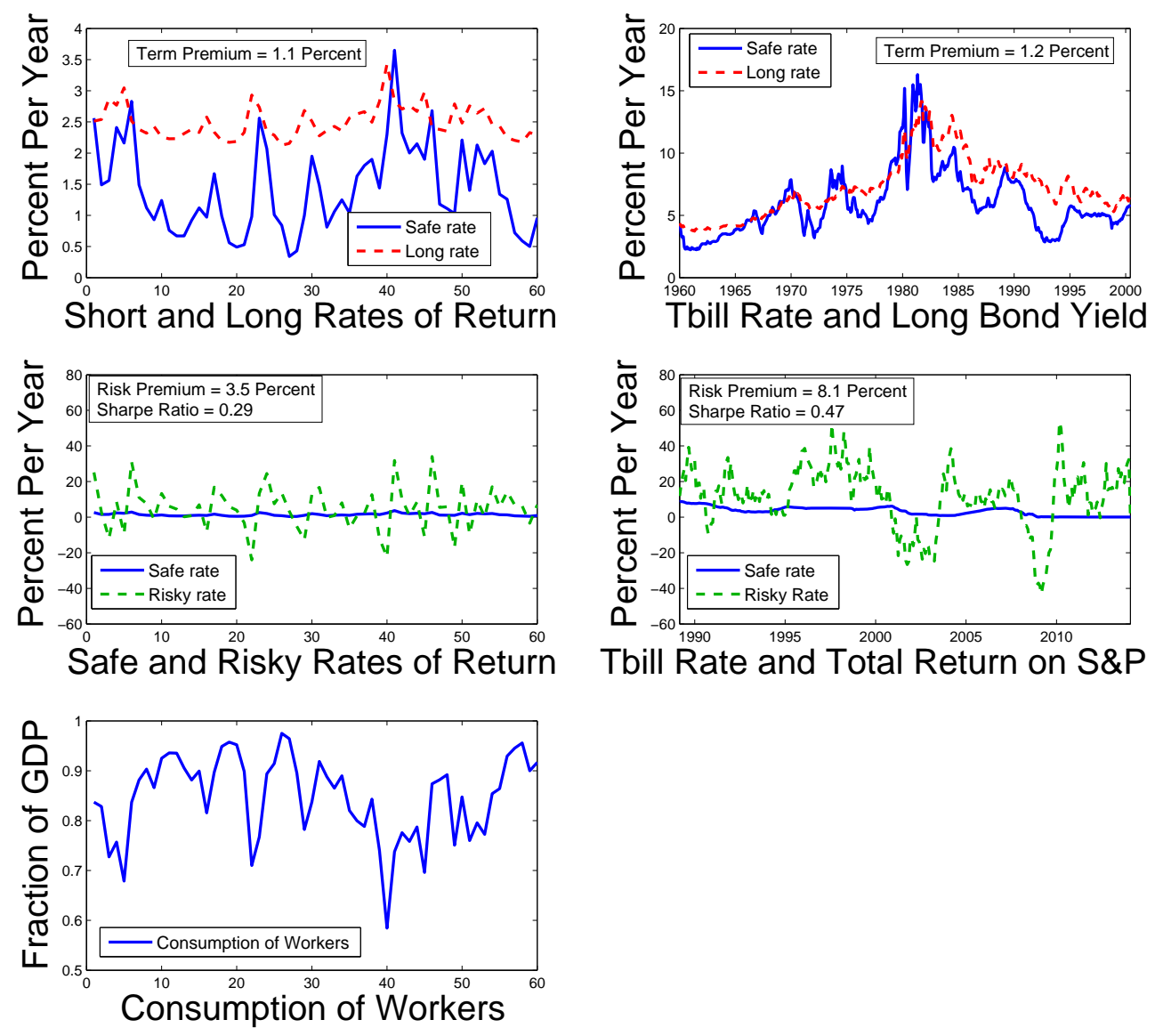

Figure 3: Simulated and Actual Data

The center left panel of Figure 3 plots the safe rate and the leveraged return to equity. In this simulated data series, the equity return was equal to $5.0 \%$ and the equity premium was equal to $3.5 \%$. The standard deviation of the leveraged equity claim was equal to 12.12 which implies that the Sharpe ratio for this simulation was 0.29 .

The calculation used to construct the stock market return assumes that the investor holds the stock for one year and sells it for price $h^{\prime}$. The fact that $h$ is volatile, partly accounts for the volatility of the simulated stock return in this figure.

There is a second factor generating volatility in simulated stock returns. To compute data for the risky return, I assumed that the stock is leveraged and I computed 
the equity return using Equation (49). Leverage increases the mean return of a risky asset; but it also increases its volatility. If the debt to equity ratio is represented by $\mu$, then a movement of $1 \%$ in the value of the underlying risky asset causes the value of the firm to move by $1 /(1-\mu) \% .^{13}$

$$
R^{E}=\frac{1}{1-\mu} R^{R}-\frac{\mu}{1-\mu} R^{S}
$$
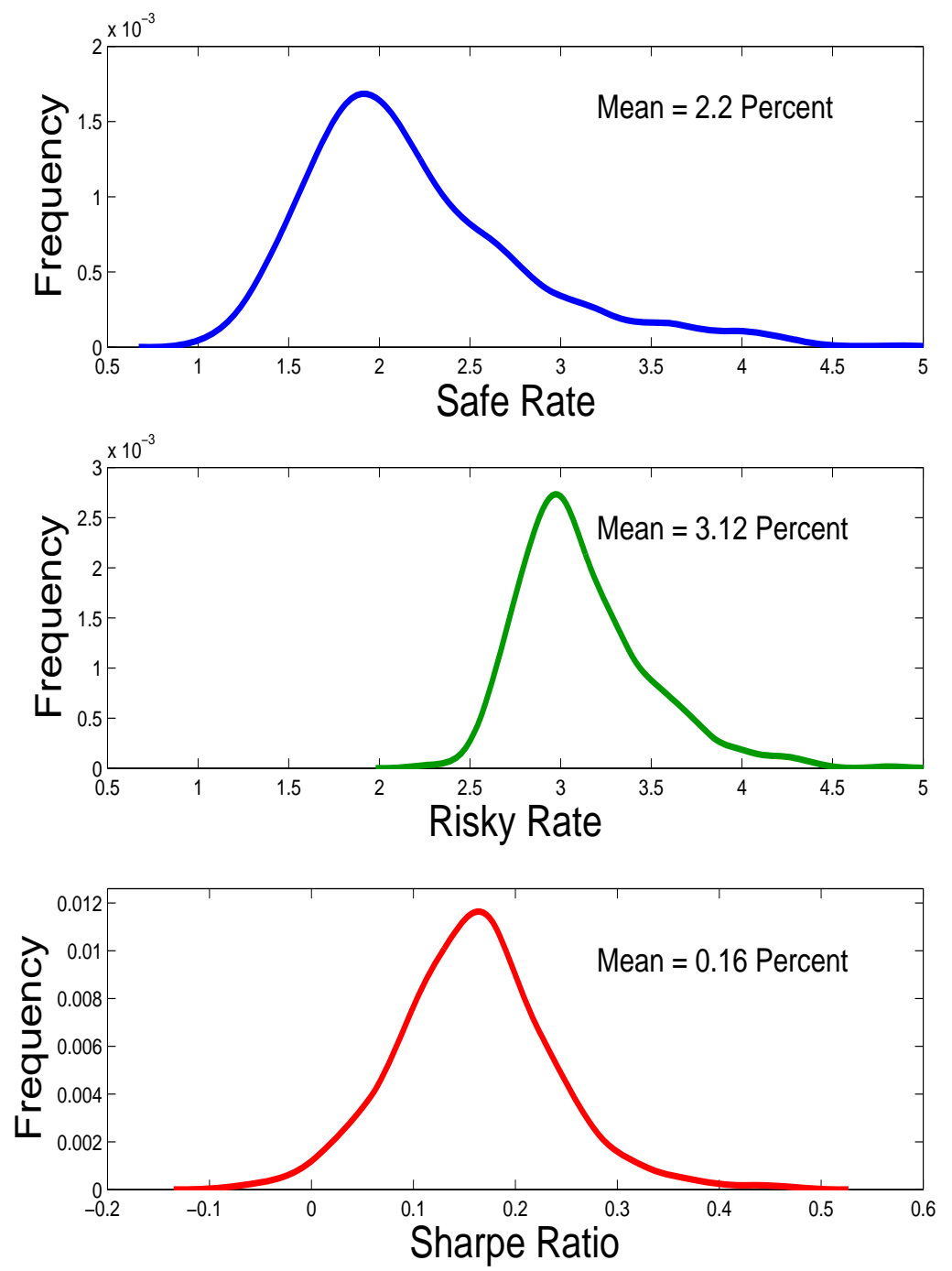

Figure 4: The Distribution of Mean Returns in 60-year Simulations

\footnotetext{
${ }^{13}$ Data on the average leverage ratio was taken from Damodaran (2014), Debt-Ratio Trade-Off Table for the U.S. File, dbtfund.xls.
} 
In the U.S., the average value of $\mu$ across all U.S. firms is roughly 0.6 which implies that the realized value of a leveraged claim should swing by approximately two and half times as much as the value of the underlying asset.

Although the model delivers a high term premium and a volatile risky rate, aggregate consumption in the model is constant and equal to 1. Agents are willing to pay a high premium on a long asset because the stochastic discount factor has a high covariance with the consumption growth of individual agents. And to generate a high covariance, the variance of consumption growth must itself be high. That fact that is reflected in the lower left panel of Figure 3 which plots the consumption of all workers.

On average, workers as a group consumed $84 \%$ of GDP each year in this sample; but that average reflects considerable year to year variation. In a bad year for the working population, consumption in this sample fell as low as 58\% of GDP and in a good year, it was as high as $97 \%$. Since $75 \%$ of the population are workers and $25 \%$ retirees, these numbers imply that in an average year, a retiree consumed $57 \%$ as much as a worker, but that fraction fluctuated with a low of $9 \%$ and high of $221 \%{ }^{14}$

Although one draw of sixty years of data displays a high equity premium, one is entitled to ask if the realization was a statistical fluke. Since the standard deviation of equity returns is so high, there is a significant probability of observing a high equity premium simply as a result of sampling error. Figure 4 investigates that possibility. The figure plots the empirical densities of the mean riskless rate, the mean leveraged equity rate and the mean Sharpe ratio in 500 replications of 60 years of data, using the parameters from Table 1. The figure illustrates that the mean Sharpe ratio is equal to 0.16 with a significant probability of observing a Sharpe ratio of 0.3 or higher.

\section{A Summary of my Results}

What has this paper achieved? We know from the work of Barro (2005) and Rietz (1988) that a model with occasional large drops in consumption can generate a large equity premium. And from the work of Gabaix (2012) and Wachter (2013) we know that the ability of the rare disaster model to explain the facts is enhanced when the probability of a disaster is time varying. But what explains sudden large drops in consumption? And are those large drops in consumption frequent enough in the data to explain an equity premium of $6 \%$ ?

\footnotetext{
${ }^{14}$ If the workers consumes a fraction $\mu$ of the endowment, the average worker receives a fraction $\mu / 3$ and the average retiree receives $(1-\mu)$, reflecting the fact that there are three workers for every retiree. The relative consumption of a retiree is $3(1-\mu) / \mu$.
} 
The first contribution of this paper is to show that disasters need not be fundamental; in a lifecycle model, they may be generated by sunspots or self-fulfilling prophecies.

We know from the work of Constantinides and Duffie (1996), Guvenen (2009) and Storesleten and Yaron (2007), that uninsurable cross-section risk can contribute to asset price volatility and to a high equity return. Guvenen (2009) has formalized that idea in a two agent model and Kubler and Schmedders (2011) come to a similar conclusion in an overlapping generations model when markets are complete but agents have differing beliefs. The equilibria in both of these papers are solved computationally.

The second contribution of this paper is to provide a simple tractable framework that can be solved analytically and that generates asset price volatility and a considerable term premium.

I show that interpersonal consumption volatility interacts with differential savings rates to generate a mean Sharpe ratio of 0.19 , which is roughly half of the observed risk premium in U.S. data. Agents in my model are risk neutral; nevertheless the model explains a large fraction of the observed risk premium.

How should one interpret the risk neutrality assumption? The fact that my agents are indifferent to consumption risk allows me to derive a simple analytic expression for the pricing kernel that would apply in a world where markets are incomplete. And since the shocks to my model are purely extrinsic, it is stretching belief to assume that there are complete markets that are contingent on their realization. Even if agents currently alive could agree on the nature of the random variables that trigger movements in asset prices, the agents that are as yet unborn would not be party to those agreements.

I conclude that many of the features I describe in this paper could be replicated in an incomplete markets model in which agents are risk averse. And in a model of that kind, the term premium that holds in my model would be supplemented by an additional term representing aversion to consumption risk.

\section{Conclusion}

The lifecycle model I have constructed in this paper is simple and elegant. There is no fundamental uncertainty and no production, and, there is a complete set of asset markets and two generations of agents. Nevertheless, my model is able to capture significant features of the behavior of real world asset markets: asset prices are volatile and the return to equity is significantly higher than the return to government bonds. 
The model is persuasive, precisely because it explains so much with so few parameters, each of which is pinned down by a few simple facts. Despite its simplicity, the model offers an elegant way to explain two important features of asset prices; asset prices are volatile and there is a substantial term premium in the data.

Although I assume a form of risk neutrality, I conjecture that the pricing kernel in my model may help applied researchers in finance to explain other features of asset pricing that I have not addressed here. My work suggests that it may be fruitful to explore a class of pricing kernels in which the stochastic discount factor is modeled as a rational polynomial in aggregate wealth. That assumption has testable implications for other areas of empirical finance including foreign exchange markets, the term structure of interest rates and the role of government asset purchases in influencing the term premium. 


\section{Appendix A. Proof of Proposition 1}

Proof. The worker and the retiree solve the following problems. First, recall the following definitions of wealth, human wealth and the budget constraint of workers;

$$
\begin{gathered}
W=h+\alpha_{1}, \\
h=1+E\left[\pi_{1} Q^{\prime} h^{\prime}\right], \\
\alpha_{1}+1-C_{1}=\pi_{1} E\left[\alpha_{1}^{\prime} Q^{\prime}\right]+\left(1-\pi_{1}\right) E\left[\alpha_{2}^{0 \prime} Q^{\prime}\right] .
\end{gathered}
$$

Summing Equations (A2) and (A3) and using the identity, (A1), leads to the following expression for the budget constraint of a worker, defined in terms of wealth, $W$

$$
W-C_{1}=\pi_{1} E\left[Q^{\prime} W^{\prime}\right]+\left(1-\pi_{1}\right) E\left[Q^{\prime} \alpha_{2}^{0 \prime}\right] .
$$

We have a similar expression for the budget constraint of a worker,

$$
\alpha_{2}-C_{2}=\pi_{2} E\left[\alpha_{2}^{\prime} Q^{\prime}\right] .
$$

Let $J(Q W)$ represent the value function of a worker and let $V\left(Q \alpha_{2}\right)$ be the value of function of a retiree. These functions are defined as follows,

$$
\begin{gathered}
J(Q W)=\max _{0 \leq C_{1} \leq W_{1}}\left\{\log \left(W-\pi_{1} E\left[Q^{\prime} W^{\prime}\right]-\left(1-\pi_{1}\right) E\left[Q^{\prime} \alpha_{2}^{\prime 0}\right]\right)\right. \\
\left.+\beta \pi_{1} J\left(E\left[Q^{\prime} W^{\prime}\right]\right)+\beta\left(1-\pi_{1}\right) V\left(E\left[Q^{\prime} \alpha_{2}^{\prime 0}\right]\right)\right\}, \\
V\left(Q \alpha_{2}\right)=\max _{0 \leq C_{2} \leq \alpha_{2}}\left\{\log \left(\alpha_{2}-\pi_{2} E\left[Q^{\prime} \alpha_{2}^{\prime}\right]\right)+\beta \pi_{2} V\left(E\left[Q^{\prime} \alpha_{2}^{\prime}\right]\right)\right\} .
\end{gathered}
$$

The fact that the expectations operator appears inside the value function distinguishes these preferences from von-Neumann Morgenstern representations of expected utility maximization.

The unknown functions $J(Q W)$ and $V\left(Q \alpha_{2}\right)$ must satisfy the following envelope conditions,

$$
\begin{gathered}
J_{W}[Q W]=\frac{1}{C_{1}}, \\
V_{\alpha}\left[Q \alpha_{2}\right]=\frac{1}{C_{2}} .
\end{gathered}
$$

In addition, they must satisfy the three sets of Euler equations for the transfer of wealth into the future,

$$
\begin{gathered}
-\frac{\pi_{1} Q^{\prime}}{C_{1}}+\beta \pi_{1} J_{W}\left(E\left[Q^{\prime} W^{\prime}\right]\right)=0, \\
-\frac{\left(1-\pi_{1}\right) Q^{\prime}}{C_{1}}+\beta\left(1-\pi_{1}\right) V_{\alpha}\left(E\left[Q^{\prime} \alpha_{2}^{\prime 0}\right]\right)=0,
\end{gathered}
$$




$$
-\frac{\pi_{2} Q^{\prime}}{C_{2}}+\beta \pi_{2} V_{\alpha}\left(E\left[Q^{\prime} \alpha_{2}^{\prime}\right]\right)=0 .
$$

These equations must hold state by state since, by assumption, there is a complete set of Arrow securities.

Since this is a logarithmic problem I will guess that the functions take the form

$$
J(Q W)=A \log (Q W), \quad V(Q \alpha)=B \log (Q \alpha)
$$

and I will verify this conjecture by finding values for the numbers $A$ and $B$ such that equations $(\mathrm{A} 8)-(\mathrm{A} 12)$ hold. By replacing the unknown functions $J(\cdot)$ and $V(\cdot)$ with their conjectured functional forms from Equation (A13) we arrive at Equations $(\mathrm{A} 14)-(\mathrm{A} 18)$.

$$
\begin{gathered}
C_{1}=\frac{W}{A}, \\
C_{2}=\frac{\alpha_{2}}{B}, \\
C_{1}=\frac{E\left[Q^{\prime} W^{\prime}\right]}{\beta A}, \\
C_{1}=\frac{E\left[Q^{\prime} \alpha_{2}^{\prime 0}\right]}{\beta B}, \\
C_{2}=\frac{E\left[Q^{\prime} \alpha_{2}^{\prime}\right]}{\beta B},
\end{gathered}
$$

where terms without a prime are functions of $S$ and terms with a prime are functions of $S^{\prime}$. Notice, that equations (A16)-(A18) are identical for all states $S^{\prime}$. This follows from risk neutrality and it is the property that allows me to construct a pricing kernel in which consumption fluctuates across sunspot states in the presence of complete markets.

The two budget equations, (A4) and (A5) and the five first order conditions (A14) - (A18) constitute seven equations in the seven unknowns, $W^{\prime}, \alpha_{2}, \alpha_{2}^{0^{\prime}}, C_{1}, C_{2}, A$ and $B$. We next solve these equations to find the values of the parameters $A$ and $B$ in terms of the fundamental parameters $\beta, \pi_{1}$ and $\pi_{2}$. First, from (A4), we have

$$
W-C_{1}=\pi_{1} E\left[Q^{\prime} W^{\prime}\right]+\left(1-\pi_{1}\right) E\left[Q^{\prime} \alpha_{2}^{0 \prime}\right]
$$

substituting for $W, Q^{\prime} W^{\prime}$ and $\alpha_{2}^{0}$ from (A14), (A16) and (A17) we have

$$
A C_{1}-C_{1}=\pi_{1} \beta A C_{1}+\left(1-\pi_{1}\right) \beta B C_{1},
$$

and canceling $C_{1}$ leads to the following expression in the two unknowns, $A$ and $B$,

$$
A\left(1-\beta \pi_{1}\right)-\left(1-\pi_{1}\right) \beta B=1 \text {. }
$$


To find a second equation in $A$ and $B$, we use the budget constraint of a retiree, Equation (14)

$$
\alpha_{2}-C_{2}=\pi_{2} E\left[Q^{\prime}\left(S^{\prime}\right) \alpha_{2}^{\prime}\right],
$$

and replace $\alpha_{2}$ and $E\left[Q^{\prime} \alpha_{2}^{\prime}\right]$ from (A15) and (A18),

$$
B C_{2}-C_{2}=\pi \beta B C_{2}
$$

which, canceling $C_{2}$, gives,

$$
B=\frac{1}{1-\beta \pi_{2}} .
$$

Substituting (A24) into (A21) gives the solution for $A$

$$
A=\frac{\left(1-\beta \pi_{2}\right)+\left(1-\pi_{1}\right) \beta}{\left(1-\beta \pi_{1}\right)\left(1-\beta \pi_{2}\right)} .
$$

To establish that $A>B$ we need to show that

$$
\begin{gathered}
A=\frac{\left(1-\beta \pi_{2}\right)+\left(1-\pi_{1}\right) \beta}{\left(1-\beta \pi_{1}\right)\left(1-\beta \pi_{2}\right)}>\frac{1}{\left(1-\beta \pi_{2}\right)}=B, \\
\Longrightarrow \frac{\left(1-\beta \pi_{2}\right)+\left(1-\pi_{1}\right) \beta}{\left(1-\beta \pi_{1}\right)}>1, \\
\Longrightarrow\left(1-\beta \pi_{2}\right)+\left(1-\pi_{1}\right) \beta>\left(1-\beta \pi_{1}\right), \\
\Longrightarrow \beta>\beta \pi_{2},
\end{gathered}
$$

which follows from the fact that $\pi_{2}<1$. Using (A25), the decisions rules for consumption of workers and retirees and the asset allocation rule for workers can be represented by equations (A27),

$$
C_{1}=\frac{\left(1-\beta \pi_{1}\right)\left(1-\beta \pi_{2}\right)}{\left(1-\beta \pi_{2}\right)+\left(1-\pi_{1}\right) \beta} W, \quad C_{2}=\left(1-\beta \pi_{2}\right) \alpha_{2}, \quad Q^{\prime} \alpha_{2}^{\prime 0}=\frac{1-\beta \pi_{1}}{1-\beta \pi_{2}} W .
$$

This establishes the form for equations (17) - (19) in Proposition 1.

To establish indifference across asset allocations, notice that (A16) - (A18) are independent of $S^{\prime}$. Substituting the consumption rules into equations (A16) and (A18) gives

$$
\frac{1}{C_{1}}=\frac{\beta}{E\left[Q^{\prime} C_{1}^{\prime}\right]}, \quad \frac{1}{C_{2}}=\frac{\beta}{E\left[Q^{\prime} C_{2}^{\prime}\right]}
$$

which completes the proof of Proposition1 1. 


\section{Appendix B. Proof of Lemma 1}

Proof. Using the decision rules, (17) and (19) and the definition of wealth, (11), we obtain the following equations for the financial wealth of workers and retirees,

$$
\alpha_{1}=A C_{1}-h
$$

and from Equation (19),

$$
\alpha_{2}=B C_{2}
$$

Since this is a closed economy with no government sector, asset market clearing and goods market clearing give the following two equations linking $\alpha_{1}$ to $\alpha_{2}$ and $C_{1}$ to $C_{2}$

$$
\begin{aligned}
& \alpha_{1}+\alpha_{2}=0, \\
& C_{1}+C_{2}=1 .
\end{aligned}
$$

Combining equations (B1) - (B4), gives the expression we seek,

$$
C_{1}=\frac{h-B}{A-B}
$$

It follows from the definitions of $A$ and $B$ that $B \leq A$ and Since $C_{1} \in[0,1]$, we must have that $h \in[B, A]$ for the consumption of workers to be feasible. This gives the domain of $\phi(\cdot)$ as $H \equiv[B, A]$. The expression for $C_{2}$ follows from the goods market clearing condition, Equation (B3). The initial condition for $h$ comes from combining equations (23) and (B1) in period 0.

\section{Appendix C. Proof of Lemma 2}

Proof. From the first order condition of a representative worker,

$$
E\left[Q^{\prime} C_{1}^{\tau \prime}\right]=\beta C_{1}^{\tau}
$$

where $C_{1}^{\tau}$ is the consumption of worker $\tau$ at date $t$ and $C_{1}^{\tau \prime}$ is the consumption of the same worker at date $t+1$ in state $S^{\prime}$. Aggregating this condition over all workers alive at date $t$ gives

$$
E\left[Q^{\prime} \tilde{C}_{1}^{\prime}\right]=\beta C_{1}
$$

where $C_{1}$ is the aggregate consumption of all workers at date $t$ and $\tilde{C}_{1}^{\prime}$ is the aggregate consumption of all workers alive at date $t$ who are still alive at date $t+1$. There is a measure $\pi_{1}$ of these agents and their consumption, plus the consumption of newborns, is equal to aggregate consumption of workers at date $t+1$;

$$
\pi_{1} \tilde{C}_{1}^{\prime}+C_{1}^{Y \prime}=C_{1}^{\prime}
$$


Here, $C_{1}^{\prime}$ is consumption of all workers at date $t+1$ and $C_{1}^{Y^{\prime}}$ is the consumption of all new born agents at date $t+1$. Replacing (C3) in (C2), using Equation (23), reproduced below,

$$
C_{1}=\phi(h) \equiv \frac{h-B}{A-B}
$$

and the fact that there is a measure $\lambda$ of newborns who consume a fraction $A^{-1}$ of aggregate human wealth,

$$
C_{1}^{Y \prime}=\lambda A^{-1} h^{\prime}
$$

leads to the expression

$$
E\left[Q^{\prime}\left(D_{2} h^{\prime}-A B\right)\right]=D_{1}(h-B),
$$

where

$$
D_{1}=A \beta \pi_{1}, \text { and, } D_{2}=A(1-\lambda)+B \lambda .
$$

Since the allocation of assets across states is indeterminate, there are many possible pricing kernels in this economy. Since the only restriction on $Q^{\prime}$ is that it satisfies Equation (C5) it follows that the function $\zeta(\cdot)$, defined as

$$
Q^{\prime}=\zeta\left(h, h^{\prime}\right) \equiv \frac{D_{1}(h-B)}{D_{2} h^{\prime}-A B},
$$

is a valid pricing kernel.

\section{Appendix D. Proof of Proposition 2}

Proof. Equation (36) follows from multiplying the left side of Equation (29) by $s^{\prime}$ and taking expectations. Solving the resulting expression for $h^{\prime}$ leads to the definition of $g(\cdot)$. The function $\psi(\cdot)$ is found by substituting (36) into (26) and rearranging terms. The fact that $s^{\prime}$ is unbounded above follows from the fact that

$$
\lim _{s^{\prime} \rightarrow \infty} g\left(h, s^{\prime}\right)=\frac{A B}{D_{2}}=\frac{A B}{(1-\lambda) A+\lambda B} \equiv B_{1} .
$$

Further, since $0<\lambda<1$, it follows that $B_{1}$ is feasible;

$$
B<\frac{A B}{(1-\lambda) A+\lambda B}=B_{1}<A \in H .
$$

These facts demonstrate that there is no upper bound on the set of feasible values of $s^{\prime}$ for any $h \in \bar{H}$. To derive a conditional lower bound on $s^{\prime}$, note that $g(\cdot)$ is decreasing in $s^{\prime}$ for $s^{\prime}>\bar{S}_{1}(h)$ where $\bar{S}_{1}(h)$ solves (40). For all values of $s^{\prime} \geq \bar{S}_{1}(h)$, $g\left(h, s^{\prime}\right) \in \bar{H}$ for all $h$. Shocks smaller than $S_{1}(h)$ can lead to infeasible values for $h^{\prime}$. 


\section{REFERENCES}

Abel, A. B. (1990): "Asset Prices under Habit Formation and Catching up with the Joneses," The American Economic Review; Papers and Proceedings, 80(2), 38-42.

- (1999): "Risk premia and term premia in general equilibrium," Journal of Monetary Economics, 43(1), 3-33.

Azariadis, C. (1981): "Self-fulfilling Prophecies," Journal of Economic Theory, 25(3), 380-396.

Balasko, Y., And D. CASs (1989): "The Structure of Financial Equilibrium with Exogenous Yields: The Case of Incomplete Markets," Econometrica, 57(1), 135162.

Bansal, R., and A. Yaron (2004): "Risks for the Long Run: A Potential Resolution of Asset Pricing Puzzles," The Journal of Finance, 59(4), 1481-1509.

Barro, R. J. (2005): "Rare Events and the Equity Premium Puzzle," NBER WP 11310.

- (2006): "Rare Disasters and Asset Markets in the Twentieth Century," Quartlerly Journal of Economics, 121(3), 823-866.

Blanchard, O. J. (1985): "Debt, Deficits, and Finite Horizons," Journal of Political Economy, 93(April), 223-247.

Campbell, J. Y. (2003): "Consumption-based asset pricing," in Handbook of the Economics of Finance, in: G.M. Constantinides 83 M. Harris $\mathcal{E}$ R. M. Stulz (ed.), Handbook of the Economics of Finance, edition 1, volume 1, chapter 13, pages 803887 Elsevier., ed. by M. H. . R. M. S. G.M. Constantinides, vol. 1, chap. 13, pp. 803-887. Handbook of the Economics of Finance, 1 edn.

Campbell, J. Y., and J. H. Cochrane (1999): "By force of habit: A consumptionbased explanation of of aggregate stock market behavior," Journal of Political Economy, 107, 205-251.

Cass, D., and K. Shell (1983): "Do Sunspots Matter?," Journal of Political Economy, 91, 193-227.

Cochrane, J. (2007): "Inflation Determination with Taylor Rules: A Critical Review," NBER WP 13410.

Constantinides, G. M. (1990): "Habit Formation: A Resolution of the Equity Premium Puzzle," Journal of Political Economy, 98(3), 519-543.

Constantinides, G. M., And D. Duffie (1996): "Asset Pricing with Heterogenous Consumers," The Journal of Political Economy, 104(2), 219-240.

Damodaran, $\quad$ A. (2014): "Online Data Source," http://pages.stern.nyu.edu/ adamodar/. 
Epstein, L., And S. Zin (1989): "Substitution, Risk Aversion and the Temporal Behavior of Consumption and Asset Returns: An Empirical Analysis.," Journal of Political Economy, 99, 263-286.

(1991): "Substitution, Risk Aversion and the Temporal Behavior of Consumption and Asset Returns: A Theoretical Framework.," Econometrica, 57, 937969.

FARMer, R. E. A. (1990): "RINCE Preferences," Quarterly Journal of Economics, 105(1), 43-60.

- (2002a): "Business Cycles with Heterogenous Agents," UCLA mimeo, Paper prepared for a conference at GREQAM on" New Perspectives of (In)Stability, the Role of Heterogeneity", Marseilles, June 2001.

- (2002b): "Fiscal Policy, Equity Premia, and Heterogenous Agents," UCLA mimeo, Paper presented to the conference "New Developments in Fiscal Policy Analysis" at Universitat Pompeu Fabra, Barcelona May 2002.

(2012): "Confidence, Crashes and Animal Spirits," Economic Journal, 122(559).

Farmer, R. E. A., C. Nourry, and A. Venditti (2012): "The Inefficient Markets Hypothesis: Why Financial Markets do not Work Well in the Real World," NBER working paper $1864 \%$

Gabaix, X. (2008): "Linearity-generating processes: A modelling tool yielding closed forms for asset prices," Working paper, New York University.

— (2012): "Variable Rare Disasters: An Exactly Solved Framework for Ten Puzzles in Macro-Finance," Quarterly Journal of Economics, 127(2), 645-700.

Gertler, M. (1999): "Government debt and social security in a lif-cycle economy," Carnegie Rochester Conference Series on Public Policy, 50, 61-110.

Guvenen, F. (2009): "A Pasimonious Macroeconomic Model for Asset Pricing," Econometrica, 77(6), 1711-1750.

Hansen, L. P., and R. Jagannathan (1991): "Restrictions on intertemporal marginal rates of substitution implied by asset returns," Journal of Political Economy, 99, 225-262.

Julliard, C., And A. Ghosh (2012): "Can Rare Events Explain the Equity Premium Puzzle?," Review of Financial Studies, 25(10), 3037-3076.

Kreps, D., and E. Porteus (1978): "Temporal Resolution of Uncertainty and Dynamic Choice Theory," Econometrica, 46, 185-200.

- (1979): "Temporal Von-Neumann Morgenstern and Induced Preferences," Journal of Economic Theory, 20, 81-109. 
Kubler, F., and K. Schmedders (2011): "Lifecycle Portfolio Choice, the Wealth Distribution and Asset Prices," University of Zurich, mimeo.

Leroy, S., and R. Porter (1981): "Stock Price Volatitlity: A Test based on Implied Variance Bounds," Econometrica, 49, 97-113.

Mehra, R., and E. C. Prescott (1985): "The Equity Premium: A Puzzle," Journal of Monetary Economics, 15, 145-161.

Rietz, T. A. (1988): "The Equity Risk Premium: A Solution," Journal of Monetary Economics, 22(1), 117-131.

Shiller, R. J. (1981): "Do stock prices move too much to be justified by subsequent changes in dividends?," American Economic Review, 71, 421-436.

Storesleten, Kjetil, C. I. T., and A. Yaron (2007): "Asset Pricing with Idiosyncratic Risk and Overlapping Generations," Review of Economic Dynamics, 10(4), 519-548.

Vissing-Jorgenson, A. (2002): "Limited Asset Market Participation and the Elasticity of Intertemporal Substitution," Journal of Political Economy, 110(4), 825853.

Vissing-Jorgenson, A., and O. P. Attanasio (2003): "Stock-Market Participation, Intertemporal Substitution, and Risk-Aversion," American Economic Review, Papers and Procedings, 93(2), 383-391.

Wachter, J. A. (2013): "Can Time-Varying Risk of Rare Disasters Explain Aggregate Stock Market Volatility?," The Journal of Finance, 68(3), 987-1035.

Woodford, M. (2001): "Fiscal Requirements for Price Stability," Journal of Money, Credit and Banking, 33(3), 669-728.

UCLA 